\title{
Exposure to microorganisms and aeroallergens among greenhouse workers worldwide and associated respiratory diseases
}

\begin{abstract}
Greenhouse operations are an important sector of the horticulture industry, also known as the Green Industry, accounting for nearly 2 million US jobs and about \$148billion in output. It is a work environment that can result in increased exposure to respiratory hazards because of its fundamentally enclosed nature. In addition, high concentrations of bioaerosols may be aerosolized by work activities in greenhouses. Thus, this is a large industry with potential for exposure to high concentrations of bioaerosols and associated respiratory diseases among workers. Our recently completed CDC-NIOSH project revealed that workers in some US greenhouses were exposed to elevated levels of airborne microbial contaminants. The prevalence of self-reported respiratory symptoms was generally higher among greenhouse workers than among controls. Studies from some European countries also reported significant associations between bioaerosol exposures and respiratory diseases among workers including occupational asthma. Bioaerosol exposure levels in greenhouses of different countries and associated allergic rhinitis and asthmatic disorders have been discussed in this review article. Large scale studies are warranted to gain a better understanding of the associations between exposures in greenhouses and the development of rhinitis and lower respiratory symptoms, particularly in the United States and many other countries. This review article will provide vital information on the current data and data gaps in exposure levels of airborne microorganisms and aeroallergens in greenhouses, associated rhinitis and other respiratory disorders, and future research directions.
\end{abstract}

Keywords: rhinitis, airborne, surveillance, bioaerosols, horticulture, epidemiological studies, pollen, allergies, nursery, advisory committee, green industry, confined building, humidity
Volume 4 Issue 3 - 2016

\author{
Atin Adhikari \\ Department of Environmental Health Sciences, Georgia \\ Southern University, Georgia
}

\begin{abstract}
Correspondence: Atin Adhikari, Department of Environmental Health Sciences, Jiann-Ping Hsu College of Public Health, Georgia Southern University, Statesboro, 30460 Georgia, Tel 9124782289, Email aadhikari@georgiasouthern.edu
\end{abstract}

Received: December 0I, 2015 | Published: April 25, 2016

\section{Green industry: employment and economic impacts}

Horticulture is a common old agricultural practice which has direct association with the daily life of human beings and our society. Greenhouse operation is an important segment of the environmental horticulture industry, which is also known as Green Industry. In a research report supported by USDA-Forest Service, National Urban and Community Forestry Advisory Committee, American Nursery and Landscape Association (ANLA) and the Associated Landscape Contractors of America, Hall et al., ${ }^{1}$ reported that estimated economic impacts of the US Green Industry are 1,964,339 jobs and $\$ 147.8$ billion in output, of which $27 \%$ is represented by the greenhouse and nursery sector. Total value added impacts of the Green Industry is largest in the Midwest region of the US. ${ }^{1}$ Based on the reports mostly available from European countries and a few reports from the US we can assume that there are considerable exposure risks for the greenhouse workers to respiratory sensitizer bioaerosols. It is also vital to note that are port of the work group convened by $\mathrm{CDC} / \mathrm{NIOSH}^{2}$ to identify priorities for hired farm workers 'occupational health surveillance and research considered greenhouse workers as one of the two top priorities for upper and lower respiratory problems (Priority \#4; Work Group Priorities for Surveillance) and also documented greenhouse workers as a special population (Priority \# 3; Work Group Priorities Regarding Design and Methods). However, little information is available so far regarding the occupational respiratory health problems of the US greenhouse workers as well as the levels of exposures to respiratory sensitizer bioaerosols in greenhouse workplaces except a few previous reports. ${ }^{3}$ Information is especially needed on the prevalence of allergic rhinitis, occupational asthma, and other respiratory health problems of greenhouse workers and the improvement of their respiratory health by identifying sources including sensitizer bioaerosols and measuring their exposure levels and assessment of respiratory disease symptoms through large-scale epidemiological studies.

\section{Particulars of a greenhouse}

A greenhouse, which is also commonly known as a glasshouse or hothouse, is a farm building built of glass and/or plastic where plants are cultivated to protect and grow outside from their normal habitat. Outside view of a US greenhouse and inside work environments are shown in Figure 1. The greenhouse heats up because the sun's inbound electromagnetic radiation warms plants, soil, and other things inside the construction. Air warmed by the heat from hot inner surfaces is retained within the greenhouse by the enclosed roof and wall. The glass used for a greenhouse works as a selective transmission medium for different spectral frequencies, which trap energy inside the greenhouse and heats both the plants and the ground, and other materials inside it. This warms the air near the ground, and this air is prevented from rising and flowing away in the confined building. Indoor air quality in greenhouses are, however, largely unknown. Greenhouses are often 
used for growing flowers, vegetables, fruits, and tobacco plants. Pests, diseases, and extremely high heat and humidity in greenhouses need to be controlled, and this artificial environment may provide a different kind of indoor environmental condition. Significant inputs of heat and light may be required, particularly for winter production of warmweather vegetables. It is largely unknown how all these artificial environmental conditions in the confined setting affect workers health and how they change biology of microorganisms and dispersal of bioaerosols that are relevant for workers' respiratory health.

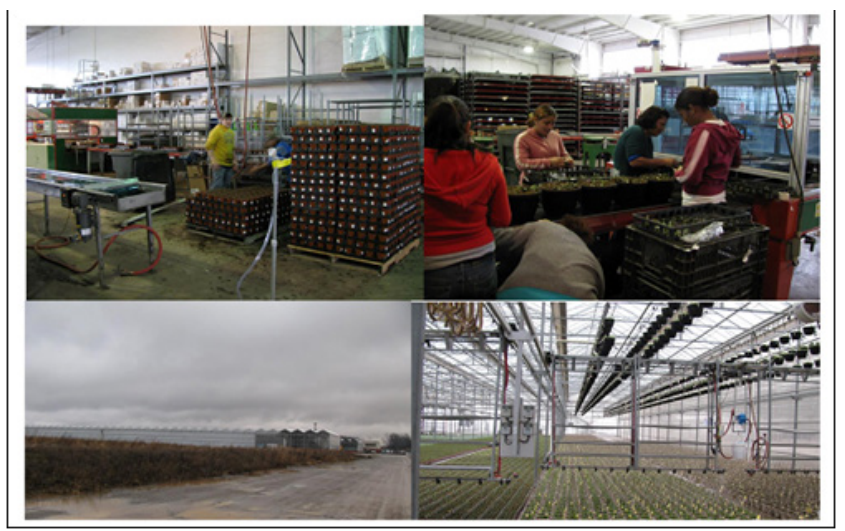

Figure I Outside view of a US greenhouse and inside work environments. Workers are often exposed to bioaerosols and organic dust and they are reluctant to use respirator masks.

\section{Bioaerosol exposures to greenhouse workers}

The greenhouse environmental conditions and flowering plants or crops are a potential hazard to the health status of greenhouse workers. The major risks of the environment are: enclosed spaces, high concentrations of airborne fungal spores and pollen grains, frequent use of biological and chemical pesticides and other chemicals, high temperature, and high humidity. ${ }^{4}$ Greenhouses, however, have received little attention in terms of air quality and potential bioaerosol risks for the workers, despite the fact that crop plants and workers therein, may be exposed to high concentration levels of airborne fungi ${ }^{5}$ and pollen from flowering plants. In confined artificial greenhouse environment the pollen density can be enhanced and may lead to unusual pollen allergies. ${ }^{6}$ Common airborne allergenic pollen grains, both perennial and seasonal, are the most frequent triggers for allergic sensitization and clinical symptomatology. The recurrent and heavy exposure to such allergenic pollen grains is one of the factors that contribute to the development of clinical symptoms of allergic rhinitis and asthma in people with a genetic tendency for atopy. Exposure to pollen of ornamental plants was believed to be much less common in the general population but can be rather disproportionate among the greenhouse workers who grow and maintain these plants. Because of the enclosed nature of greenhouse workplaces, seasonal variations of these biohazard exposure levels are also different from ambient environments and may depend more on ventilation of these spaces than on traditional environmental changes associated with seasons in ambient environmental conditions. Bioaerosols including fungal spores and pollen grains released in the greenhouse air can remain in a very high concentration level because of the slow aerial dilution and thus may pose highly increased exposure risks for the workers. Rodolfi et al., ${ }^{5}$ stated that the adverse health consequences of continued exposure of greenhouse workers to potentially pathogenic fungi should not be underestimated. In a review, Monsó ${ }^{7}$ stated that air contamination by molds inside greenhouses is facilitated by high indoor temperature and humidity.
Even though many investigators reported occupational allergy and asthma from pollen and molds in greenhouses, little information is available on the exposure levels of these bioaerosols in greenhouses from these studies. Except for the studies of Monsó et al., ${ }^{8}$ Radon et al., ${ }^{9}$ Madsen ${ }^{10}$ in European countries, to our knowledge, no other study has attempted to measure health-related bioaerosols and their personal exposures in greenhouses. This lack of information is particularly common in the United States. In 1982 Burge et al. ${ }^{11}$ did a few measurements of bioaerosols at two greenhouses of the University of Michigan Botanical Gardens while evaluating indoor plantings as mold and pollen allergen exposure sources at seventeen homes. They studied airborne viable fungi, bacteria, and actinomycetes using an Andersen Sampler. They found that in contrast to airborne bacteria and actinomycetes levels of fungi were significantly increased (geometric mean increased 1.2 to 15.4 times) during watering in greenhouses, especially for Cladosporium, Aspergillus, and Penicillium species. This observation of Burge et al. ," indicates that different work tasks in a greenhouse may be significantly related to bioaerosol exposure risks and justified further investigations on the exposure levels during different activities in greenhouses. Radon et al., ${ }^{9}$ investigated bioaerosols (except pollen) in Spanish greenhouses. Exposure to airborne microorganisms and endotoxin was determined by filtration based sampling during four different activities of the workers: spraying pesticides, cutting flowers, watering, and work in storage area. Polycarbonate filters with a pore size of $0.4 \mu \mathrm{m}$ and diameter of $25 \mathrm{~mm}$ were placed on cellulose support pads and sealed in sterile polypropylene air monitoring cassettes. Airborne concentration of total fungi was $1.1 \times 10^{6} \mathrm{spores} / \mathrm{m}^{3}$ and concentration of viable fungi was $8.3 \times 104 \mathrm{CFU} / \mathrm{m}^{3}$. The predominant fungal taxa recovered by Radon et al., ${ }^{9}$ were species of Cladosporium (83.8\%) and Botrytis $(32.4 \%)$. Airborne concentration of total bacteria was $1.5 \times 10^{7} \mathrm{cells} / \mathrm{m}^{3}$ and concentration of viable bacteria was $8.3 \times 10^{4} \mathrm{CFU} / \mathrm{m}^{3}$. Endotoxin concentration was $0.36 \mathrm{ng} / \mathrm{m} 3$. As a part of the European Farmers' Study (European Union Concerted Action "Prevalence and Risk Factors for Airway Diseases in Farmers") Monsó et al., ${ }^{8}$ investigated workers' personal exposure to airborne microorganisms, total dust, and endotoxin in 34 greenhouses in Spain. Mold concentrations were high in most cases with higher frequencies of Cladosporium sp., Penicillium sp., Botrytis sp., Acremonium sp., Aspergillus sp., and Alternaria sp. Endotoxin levels were low, sometimes failing to reach the detection limit. Median concentrations of airborne molds, bacteria, and endotoxin were $5000 \mathrm{CFU} / \mathrm{m}^{3}, 2300 \mathrm{CFU} /$ $\mathrm{m}^{3}$, and $0.32 \mathrm{ng} / \mathrm{m}^{3}$, respectively. The authors found more cases of workers' sensitization to flower allergens from greenhouse plants (Chrysanthemum, Solidago, Helianthus, Gladiolus, Narcissus, and Hyacinthus) compared to molds, however, they did not investigate exposure levels to airborne pollen. Probably this was the reason for the insignificant relationship between air contaminants and wheezing or allergen sensitization reported by them. Radon et al., ${ }^{9}$ Monsó et al., ${ }^{8}$ found $2.8 \mathrm{EU} / \mathrm{m}^{3}$ median endotoxin level in the greenhouses (data from ng are converted to EU) of Spain; however, Madsen ${ }^{12}$ found much higher endotoxin level $\left(\right.$ median $=13.2 \mathrm{EU} / \mathrm{m}^{3}$ ) in the greenhouses of Denmark. This observation supports our assumption that bioaerosol exposure conditions in different countries can be different and strengthens the need for an independent extensive study in the greenhouses of the Midwest US. Use of an inhalable sampler by Madsen ${ }^{12}$ an advancement of the methodology compared to previous researchers and we will follow this sampling method in this proposed study. Recent studies from Denmark showed that personal exposure to fungi in greenhouses ranged between $1.8 \times 102$ and $3.4 \times 106 \mathrm{CFU} /$ $\mathrm{m} 3$ and to bacteria between $1.6 \times 10^{1}$ and $4.2 \times 10^{5} \mathrm{CFU} / \mathrm{m}^{3}{ }^{13}$ The researchers of this study also found that exposure to dust, endotoxin, fungi, and bacteria differed between seasons. 
Except these reviewed studies, bioaerosol exposure data from greenhouses of other countries are almost lacking. We have conducted a pilot study recently in US greenhouses. ${ }^{3}$ This study demonstrated that mean concentrations of inhalable culturable fungi in three greenhouses were $429-3584 \mathrm{CFU} / \mathrm{m}^{3}$ in winter and 3939-9947CFU/ $\mathrm{m}^{3}$ in summer from five simultaneous measurements with Button samplers. Additional three measurements near major work areas in green houses showed a mean concentration range of 2427-4597CFU/ $\mathrm{m}^{3}$ in summer and $846-10535 \mathrm{CFU} / \mathrm{m}^{3}$ in winter. Therefore, exposure conditions and microbial species components of the bioaerosols in the greenhouses of different countries, however, can be largely different from the greenhouses in European and Asian countries. Furthermore, none of the previous studies investigated airborne pollen in the greenhouses although there are numerous reports on the sensitization of greenhouse workers to the pollen allergens from the plants growing there.

\section{General respiratory health effects of bioaerosols which are common in greenhouses}

Respiratory allergy, asthma, and infections are major groups of diseases associated with bioaerosol exposures. ${ }^{14}$ Agricultural workers are at increased risk of occupational respiratory diseases. ${ }^{15}$ The role of airborne fungi in the development of respiratory allergies and asthma has been established by previous studies. ${ }^{16-18}$ More than 80 genera of fungi have been associated with respiratory tract allergy. ${ }^{19,20}$ In addition to airborne fungi and pollen, high concentrations of bacteria, actinomycetes, and endotoxin have been reported in the air of farm workplaces. ${ }^{21-23}$ Thermophilic bacteria and spore forming actinomycetes are well-known sources of allergens. ${ }^{14}$ Most bacteria, however, are not very potent allergens, but their cell-wall components, such as endotoxin and peptidoglycans are important pro-inflammatory agents which may induce respiratory symptoms. ${ }^{14}$ Endotoxin is a cell wall component from Gram-negative bacteria, and is composed of lipopolysaccharides as a main constituent. Inhaled endotoxin contributes significantly to the induction of airway inflammation and dysfunction, ${ }^{24}$ and many occupational studies have shown positive associations between endotoxin exposure and respiratory disorders including asthma-like syndrome, chronic airway obstruction, byssinosis, bronchitis, and increased airway responsiveness. ${ }^{12}$ Endotoxin has also been recognized as a causative factor in the aetiology of occupational lung diseases including non-allergic asthma (unlike pollen and molds) and organic dust toxic syndromes. ${ }^{14}$ Little information is available on the health effects of (1à3)- $\beta$-D-glucan in agricultural environments; however, its association with dry cough, cough associated with phlegm, hoarseness, and atopy have been reported in indoor environments. ${ }^{25-28}$

\section{Occupational allergy and asthma among greenhouse workers associated with pollen and molds}

Based on the European studies on respiratory allergy and asthma among greenhouse workers, pulmonary hazards in a greenhouse may include organic dusts including pollens grains, fungal spores, and other plant products, infectious agents (fungi, bacteria, and viruses), actinomycetes, endotoxin, glucans, toxic chemicals, and pesticides. Fungal spores can be easily liberated in damp areas of greenhouses and render these workplaces potentially unhealthy for allergic individuals. ${ }^{29}$ Release of a huge load of pollen grains from flowering plants in enclosed greenhouse spaces can create risks of allergic rhinitis and occupational asthma for workers.

\section{Occupational allergy}

Recently, allergic sensitization to many fungi including Cladosporium, Penicillium, Aspergillus, and Alternaria has been reported in about $20 \%$ of the greenhouse flower growers in Spain by Monsó et al. ${ }^{8}$ In a cross-sectional study of 75 flower growers in Israel Goldberg et al., ${ }^{30}$ found sensitization to flower pollen allergens in half of the subjects, a prevalence much higher than in the reference population. They also found that $15 \%$ flower growers left the occupation because of unbearable symptoms, suggesting that their sensitization was clinically significant. A wide range of flowers with antigenic capabilities were reported in the studies of Goldberg et al., ${ }^{30}$ and Monsó et al., ${ }^{8}$ including members of the Asteraceae, Ranunculaceae, Liliaceae, Scrophulariaceae, and Genetiaceae families. Groenewoud et al., ${ }^{31}$ reported a $49.4 \%$ incidence of occupational allergy (main symptom being rhinitis) to Chrysanthemum pollen in greenhouses in the Netherlands. Another two studies from the Netherlands reported occupational allergy and primary sensitization to bell pepper pollen in greenhouses (Groenewoud et al.;1 Vermeulen et al. ${ }^{32}$ Gil et al., ${ }^{33}$ from Switzerland reported occupational allergy from eggplant pollen and worker's respiratory function impairment in the greenhouses of eggplant. Suzuki et al. ${ }^{34}$ from Japan found that $18.9 \%$ Chrysanthemum flower handlers had both allergic rhinitis and bronchial asthma and $42.5 \%$ had allergic rhinitis with positive scratch tests against the pollen extract. Another study from Japan by Ueda et al., ${ }^{35}$ found allergic symptoms in 58\% workers engaged in growing flowers.

\section{Occupational asthma}

Almost 70years ago, Rackeman et al., ${ }^{36}$ from the Harvard Medical School reported four cases of severe asthma among the greenhouse workers sensitized to Cladosporium, a common airborne fungus. Monsó et al., ${ }^{8}$ found that almost one quarter of the sensitized greenhouse workers in their study suffered from occupational asthma and allergens from molds and flowers were significantly associated with the disease. They concluded that the cultivation of flowers and/ or ornamental plants inside greenhouses may cause occupational asthma in up to $8 \%$ of the greenhouse growers through sensitization to flower allergens and workplace molds. These observations agreed with the published reports of individual cases of sensitization and asthma symptoms in flower handlers in different countries including Finland, Spain, Netherlands, and Brazil. ${ }^{37-42}$ In another study involving 4,793 European crop farmers, Monsó et al., ${ }^{7}$ found in a multivariate analysis adjusting for age, sex, smoking, country, and exposure to other plants and livestock, that flower growing was a risk factor for asthma (odds ratio [OR]: $2.1 ; 95 \%$ confidence interval [CI]: 1.1-3.9). Van der Zee et al., ${ }^{43}$ reported an outbreak of occupational allergic asthma among the greenhouse workers in a Madagascar Jasmine nursery in the Netherlands. Dyspnea, wheezing, and eye and upper airways symptoms (conjunctivitis and rhinitis) during stay in the greenhouse were observed by the authors. A NIOSH supported collaborative study between the scientists of Croatia and USA studied respiratory health of the greenhouse workers in Croatia Zuskin et al., ${ }^{4}$ found that greenhouse workers developed acute and chronic respiratory symptoms as well as lung function impairment (significant reduction in FEV1, FEF50, and FEF25) related to their working conditions in closed greenhouse spaces. The authors pointed out that the danger of inhaling airborne pollen grains emitted from plants grown in a greenhouse is considerable. In another collaborative study, the scientists of Europe and USA Monsó et al., ${ }^{44}$ investigated risk factors for respiratory symptoms in almost 9000 European and Californian farmers and found that flower growing was significantly associated with asthma (adjusted OR: 1.71, 95\% CI:1.06-2.77), toxic 
pneumonitis (adjusted OR 1.75, 95\% CI: 1.29-2.38) and chronic bronchitis (adjusted OR 1.75, 95\% CI: 1.29-2.38). In this study, working inside greenhouses emerged to be a significant risk factor for chronic bronchitis in non-smokers (adjusted OR 1.59, 95\% CI: $1.02-2.48$ ), who reported a $15 \%$ prevalence of respiratory symptoms if working inside, much higher than the $9 \%$ prevalence reported in non-smoking outdoor farmers.

In one of our recent pilot studies we examined the associations between the exposures to different bioaerosol components and workplace characteristics with the respiratory symptoms and allergic sensitizations among the greenhouse workers in three greenhouses in the US. ${ }^{3}$ The prevalence of respiratory symptoms was investigated using a cross-sectional study design. A standardized questionnaire was used to collect data from the greenhouse workers (exposed group; $n=35$ ) and office workers (non-exposed group; $n=14$ ) in participating greenhouses. Information on the symptoms of past and present respiratory illnesses, including episodes of cough and phlegm, wheezing and breathlessness, sinus problems, pneumonia, acute and chronic bronchitis and emphysema, and allergic conditions, such as allergicrhinitis and asthma, were self-reported by each participant. A physician's diagnosis of rhinitis (hay fever), asthma, bronchitis and emphysema, pneumonia and sinus trouble was recorded. With respect to prevalence of respiratory symptoms, none of the comparisons between workers and controls reached statistical significance probably due to small subject population, however, there was a discernible trend observed. The trend showed a higher prevalence of respiratory symptoms among workers in most of the comparisons.

\section{Pollen and mold exposure vs. the work performance of employees with allergic rhinitis: potential impact in greenhouse workers}

In a nationwide study in collaboration with the MacArthur Foundation's National Survey of Daily Experience (NSDE) Kessler et al., ${ }^{45}$ found that pollen and mold exposure impairs the work performance of employees with allergic rhinitis in the United States. High grass pollen had the largest OR in predicting impaired work quality (9.9, with a $95 \%$ CI of 3.3 to 29.8 ), whereas high mold had the highest OR in impaired work quantity (18.1 with $95 \%$ CI of 4.1 to 72.9). Kessler et al., ${ }^{45}$ reported that average estimated monthly salary-equivalent work impairment costs associated with pollen/ mold exposure for each allergy sufferer was between $\$ 109$ and $\$ 156$, with an annualized national projection of between \$5.4billion and \$7.7billion. In another study, Groenewoud et al., ${ }^{31}$ found that bell pepper greenhouse employees are impaired in rhinitis-specific quality of life because of their sensitization to bell pepper pollen. They investigated the relative influence of sensitization to bell pepper pollen, predatory mite Amblyseius cucumeris, and common allergens and found that bell pepper pollen had a significant negative effect on all the domain and quality of life scores. The other allergens, however, had no effect on the quality of life. A significant decrease in all the rhinitis scores was found outside the flowering period. Occasional single cases of occupational asthma due to greenhouse molds have also been reported, confirming the impact of greenhouse sensitization by these allergens on the workers' daily life. ${ }^{46} \mathrm{~A}$ recent study, in fact, showed that workers with rhinitis at baseline were more expected to leave their job in bell pepper cultivation for another job $(\mathrm{OR}=1.62$, 95\% CI 0.95-2.75) and bell pepper greenhouse workers with workrelated nasal symptoms experience a substantial improvement in rhinitis-related quality of life after leaving the work environment. ${ }^{47,48}$ All these observations call for further investigation of the possible potential role of exposures to pollen grains (especially the pollen from ornamental flowering plants whose allergenic sensitivity is still unknown) and other aeroallergens (including mold spores and some bacteria) in greenhouses in relation to workers performance.

\section{Acknowledgements}

None.

\section{Conflict of interest}

The author declares no conflict of interest.

\section{References}

1. Hall CR, Hodges AW, Haydu JJ. Economic Impacts of the Green Industry in the United States. 2005.

2. CDC/National Institute for Occupational Safety and Health (NIOSH). New Directions in the Surveillance of Hired Farm Worker Health and Occupational Safety: A Report of the Work Group Convened by NIOSH, 1995, to Identify Priorities for Hired Farm Worker Occupational Health Surveillance and Research.

3. Adhikari A, Gupta J, Wilkins III JR, et al. Air borne microorganisms, endotoxin, and (1->3)- $\beta-\mathrm{D}$ glucan, exposure in greenhouses and respiratory symptomsamong workers. Ann Occup Hygiene. 2011;55(3):272-285.

4. Zuskin E, Schachter EN, Mustajbegovic J. Respiratory function in greenhouse workers. Int Arch Occup Environ Health. 1993;64(7):521526

5. Rodolfi M, Lorenzi E, Picco AM. Study of the occurrence of greenhouse micro fungi in a botanical garden. Journal of Phytopathology. 2003;151(11-12):591-599.

6. Bessot JC, Blaumeiser M, Kopferschmitt MC, et al. Occupational asthma in an agricultural setting. Rev Mal Respir. 1996;13(3):205-215.

7. Monsó E. Occupational asthma in greenhouse workers. Curr Opin Pulm Med. 2004;10(2):147-150.

8. Monsó E, Magarolas R, Badorrey I, et al. Occupational asthma in greenhouse flower and ornamental plant growers. Am J Respir Crit Care Med. 2002;165(7):954-960.

9. Radon K, Danuser B, Iversen M, et al. Air contaminants in different European farming environments. Ann Agric Environ Med. 2002;9(1):4148.

10. Madsen AM. Airborne endotoxin in different background environments and seasons. Ann Agric Environ Med. 2006;13(1):81-86.

11. Burge HA, Solomon WR, Muilenberg ML. Evaluation of indoor plantings as allergen exposure sources. J Allergy Clin Immunol. 1982;70(2):101-108.

12. Madsen AM. Airborne endotoxin in different background environments and seasons. Ann Agric Environ Med. 2006;13(1):81-86.

13. Thilsing T, Madsen AM, Basinas I, et al. Dust, endotoxin, fungi, and bacteria exposure as determined by work task, season, and type of plant in a flower greenhouse. Ann Occup Hyg. 2015;59(2):142-157.

14. Douwes J, Thorne P, Pearce N, et al. Bioaerosol health effects and exposure assessment: progress and prospects. Ann Occup Hyg. 2003;47(3):187-200.

15. May JJ, Kullman GJ. Agricultural safety and health in a new century. American Journal of Industrial Medicine. 2002;42(2):1-2. 
16. Ellis MB. More dematiaceous Hyphomycetes. Netherlands Journal of Plant Pathology. 1977;83(2):90-91.

17. Malling HJ. Diagnosis and immunotherapy of mould allergy. IV. Relation between asthma symptoms, spore counts and diagnostic tests. Allergy. 1986;41(5):342-350.

18. Strachan DP. Damp housing and childhood asthma: validation of reporting of symptoms. Br Med J. 1988;297(6658):1223-1226.

19. Horner WE, Helbling A, Salvaggio JE, et al. Fungal allergens. Clin Microbiol Rev. 1995;8(2):161-179.

20. Latgé JP, Paris S. The fungal spore: reservoir of allergens. In: Cole GT, Hoch HC, editors. The fungal spore and disease initiation in plants and animals. USA: Plenum Press; 1991. p. 379-401.

21. Krysinska-Traczyk E, Skorska C, Prazmo Z, et al. Exposure to airborne microorganisms, dust and endotoxin during flax scutching on farms. Ann Agric Environ Med. 2004;11(2):309-317.

22. Skorska C, Sitkowska J, Traczyk KE, et al. Exposure to airborne microorganisms, dust and endotoxin during processing of peppermint and chamomile herbs on farms. Ann Agric Environ Med. 2005;12(2):281-288.

23. Lee SA, Adhikari A, Grinshpun SA, et al. Personal exposure to airborne dust and microorganisms in agricultural environments. J Occup Environ Hyg. 2006;3(3):118-130.

24. Pirie RS, Collie DD, Dixon PM, et al. Inhaled endotoxin and organic dus particulates have synergistic proinflammatory effects in equine heaves (organic dust-induced asthma). Clin Exp Allergy. 2003;33(5):676-683.

25. Rylander R, Norrhall M, Engdahl U, et al. Airways inflammation, atopy, and (1-3)-beta-D-glucan exposures in two schools. Am J Respir Crit Care Med. 1998;158(5 Pt 1):1685-1687.

26. Rylander R. Indoor air-related effects and airborne $(1 \rightarrow 3)$-beta-Dglucan. Environ Health Perspect. 1999;107(Suppl 3):501-503.

27. Rylander R, Fogelmark B, McWilliam A, et al. $(1 \rightarrow 3)$-beta-Dglucan may contribute to pollen sensitivity. Clin Exp Immunol. 1999;115(3):383-384

28. Thorn J, Rylander R. Airways inflammation and glucan in a rowhouse area. Am J Respir Crit Care Med. 1998;157(6 Pt 1):1798-1803.

29. Hyde HA. Atmospheric pollen grains and spores in relation to allergy. II. Clin Allergy. 1973;3(2):109-126.

30. Goldberg A, Cohen CR, Waisel Y. Allergic responses to pollen of ornamental plants: high incidence in the general atopic population and especially among flower growers. J Allergy Clin Immunol. 1998;102(2):210-214.

31. Groenewoud GC, de Jong NW, van Oorschot-van Nes AJ, et al. Prevalence of occupational allergy to bell pepper pollen in greenhouses in the Netherlands. Clin Exp Allergy. 2002;32(3):434-440.

32. Vermeulen AM, Groenewoud GC, De Jong NW, et al. Primary sensitization to sweet bell pepper pollen in greenhouse workers with occupational allergy. Clin Exp Allergy. 2003;33(10):1439-1442.
33. Gil M, Hogendijk S, Hauser C. Allergy to eggplant flower pollen. Allergy. 2002;57(7):652.

34. Suzuki S, Kuroume T, Todokoro M, et al. Chrysanthemum pollinosis in Japan. Int Arch Allergy Appl Immunol. 1975;48(6):800-811.

35. Ueda A, Ueda T, Matsuhita T, et al. Prevalence rate of risk factors for allergic symptoms among inhabitants in rural district. Sangyo Igaku. 1987;29(1):3-16.

36. Rackemann FM, Randolph TG, Guba EF. The specificity of fungus allergy. Journal of Allergy. 1938;9(5):447-453.

37. Piirilä $\mathrm{P}$, Kanerva L, Alanko K, et al. Occupational IgE-mediated asthma, rhinoconjunctivitis, and contact urticaria caused by Easter lily (Lilium longiflorum) and tulip. Allergy. 1999;54(3):273-277.

38. Kanerva L, Makinen-Kiljunen S, Kiistala R, et al. Occupational allergy caused by spathe flower(Spathiphyllum wallisii). Allergy. 1995;50(2):174-178.

39. Giavina-Bianchi PF Jr, Castro FF, Machado ML, et al. Occupational respiratory allergic disease induced by Passiflora alata and Rhamnus purshiana. Ann Allergy Asthma Immunol. 1997;79(5):449-454.

40. Vidal C, Polo F. Occupational allergy caused by Dianthus caryophillus, Gypsophila paniculata, and Lilium longiflorum. Allergy. 1998;53(10):995-998.

41. De Jong NW, Vermeulen AM, Gerth van Wijk R, et al. Occupational allergy caused by flowers. Allergy. 1998;53(2):204-209.

42. Miesen WM, van der Heide S, Kerstjens HA, et al. Occupational asthma due to IgE mediated allergy to the flower Molucella laevis (Bells of Ireland). Occup Environ Med. 2003;60(9):701-703.

43. Van der Zee JS, De Jager KS, Kuipers BF, et al. Outbreak of occupational allergic asthma in a Stephanotis floribunda nursery. J Allergy Clin Immunol. 1999;103(5 Pt 1):950-952.

44. Monsó E, Schenker M, Radon K, et al. Region-related risk factors for respiratory symptoms in European and Californian farmers. Eur Respir J. 2003;21(2):323-331.

45. Kessler RC, Almeida DM, Berglund P, et al. Pollen and mold exposure impairs the work performance of employees with allergic rhinitis. Ann Allergy Asthma Immunol. 2001;87(4):289-295.

46. Farruggia E, Bellia M. [Occupational allergic asthma in greenhouses. Report of a clinical case]. Med Lav. 2001;92(3):203-205.

47. Gerth van Wijk R, Patiwael JA, de Jong NW, et al. Occupational rhinitis in bell pepper greenhouse workers: determinants of leaving work and the effects of subsequent allergen avoidance on health-related quality of life. Allergy. 2011;66(7):903-908.

48. Hyde HA. Atmospheric pollen grains and spores in relation to allergy II. Clin Allergy. 1973;3(2):109-126. 